\title{
Agricultural activities and the market for agricultural business products
}

\author{
Cheng Mou Souy \\ Human Resources University, Phnom Penh, Cambodia
}

\begin{abstract}
Basically, there are not many farmers who can sell their own products to the market, both domestic and foreign markets, because these markets are generally too far away for them. Individual farmers cannot contact buyers in these markets because they do not have adequate means of transportation and do not have the necessary knowledge or facilities for various purposes, such as packaging, storage, processing and nothing else related to the marketing. Therefore, a good and efficient trading system for agricultural products is needed in supporting the success / success of the market for agricultural products. So that agriculture is not only viewed in a narrow sense, where the agricultural sector is very large and wide, it is necessary to convey the history of agriculture and its development for the advancement of agriculture and the application of technology in agriculture. Farmers need knowledge in terms of crop management and good management in the context of the welfare of the farmers, where we know that many farmers feel disadvantaged in the sale or marketing of their agricultural products.
\end{abstract}

Keywords: Agriculture, Agricultural Market, Farm Production

\section{Introduction}

Agricultural activities began to be known when humans began to take part in the process of plant and animal activities and their arrangement to meet needs. The level of agricultural progress ranging from gathering and hunting, primitive agriculture, traditional agriculture to modern agriculture.

Many agricultural actors do not know clearly about the history of agriculture, the main thing is that most of them are just doing what the people before them have done to carry out agricultural activities. Along with agricultural activities, it must not be separated from the existence of business or business activities in the context of selling or utilizing agricultural products, so it is not uncommon for them to manage or sell post-harvest production for daily needs or even become a separate business by some people who are able to run it (Phillips et al., 2000 Arah et al., 2015). So with the compilation of this paper the authors hope to provide a little insight into the history of agriculture and how about the management of post-harvest production in the world of agriculture.

\section{Understanding Agricultural Science and Agricultural History}

Agriculture is a type of production activity based on the growth process of plants and animals. Agriculture in a narrow sense is called people's agriculture, while agriculture in a broad sense includes agriculture in the narrow sense, forestry, livestock and fisheries. These 
are all important things. Broadly speaking, the notion of Agriculture can be summarized into (1) Production Process; (2) Agriculture or businessmen; (3) Land on which the business is located; (4) Farm business. The beginning of agricultural activities occurred when humans began to take part in the process of plant and animal activities and their arrangement to meet needs. The level of agricultural progress ranging from gathering and hunting, primitive agriculture, traditional agriculture to modern agriculture.

Agriculture can be given in both a limited and a broad sense. In a limited sense, agriculture is the processing of plants and their environment in order to provide a product. Whereas in a broad sense, agriculture is managing crops, livestock, and fish in order to provide a product much better than if the plants, livestock or fish are allowed to live naturally.

Agricultural science is the study of how to manage crops, livestock, fish and the environment in order to provide maximum results. Science has now developed into a very broad agricultural science, not only studying crop management (Altieri, 2002; Pretty et al 2011). Animal husbandry is not only studying livestock science, fisheries science is not only studying the science of managing fish and other aquatic animals. Therefore, these three sciences are included in agricultural science in a broad sense, while imu which only study plant management is usually called agricultural science in a limited sense.

This agricultural science came into existence cannot be said with certainty, which obviously did not coincide with the existence of humans in the world. The first humans in the world did not have difficulty making ends meet because their kebutuha was very simple (Marra., 2003; Alemanno, 2007). All the necessities of life were already available in nature in quite a large number, when compared to the number of humans that existed at that time. Previous human needs were only two, namely maintaining life and maintaining offspring. The need to survive is done by eating. This food is widely available, both in the form of parts of plants and animals, including fish. Meanwhile, in meeting the needs of maintaining offspring, sex is done. In this case they do not experience any difficulties because from the beginning God created humans, and their subsequent descendants, some were female and some were male.

Increasing the number of humans will accelerate the depletion of food in their natural surroundings. To meet their needs, they move from place to place. Furthermore, this movement can no longer solve the problem because human numbers are no longer balanced with natural food supplies. Finally, they begin to think to find out why the problem arises and to try to solve it by means or actions that are currently very simple. Humans gather food and hunt in Southeast Asia in this case means they do not stay long in one place. Their living places are generally in caves or holes at the foot of rock cliffs. Usually they eat leaves, flowers, tubers, fruit bark, tubers and plant roots. Many travelers also possessed the knowledge to remove toxins from foodstuffs and how to preserve them.

\section{Primitive, Traditional and Modern Agriculture}

In Southeast Asia there are various groups of people from various economic levels which are very diverse. The first humans to occupy the tropical forest area around the South China Sea were Alitic or Preopaleolitic. They are a group of food gatherers who get food by collecting edible plants, besides that they also hunt and catch fish. In this day and age there are still groups of humans who apply the life of the prepeleolithic or paleolithic age and their life is usually still isolated. When human gatherers and hunters began to try to get plants as a source of food, a link began to occur between the period of gatherers and hunters and primitive agriculture. For example, people who really like durian will stay near the durian tree 
to prevent monkeys or other animals from eating up the durian. The people also replant wild tendrils or tubers into the ground after they harvest the tubers. In this way the plant can grow and develop. The postponement is one step towards Promitive agriculture. After centuries of gathering plants, they finally gained knowledge about plant life.

The difference between primitive agriculture and more advanced agriculture is evident in land use. In primitive agriculture, land use is carried out in shifts. A plot of land is planted about once or twice then the land is abandoned. They are looking for new land in the form of thickets or forests to be cleared and then planted once or twice and then abandoned again (Smith, 1975; Jacob, 2010). In primitive agriculture, logs that have been felled are not thrown away and planted, but burned. This agricultural system is known as huma or shifting cultivation.

In advanced agriculture, land use is carried out on the same land every year. Therefore, it is called permanent agriculture. Permanent agriculture depends on the amount of human effort in regulating plant growth, while its exploitation motivation can be distinguished from modern agriculture. In traditional agriculture, farmers accept soil conditions, rainfall and crop varieties as they are or as nature provides them. Assistance to plant growth is only to a certain extent. For example, using water that is available from nature or provided through irrigation systems, removes weeds, and protects plants from disturbance by wild animals or insects in a way that has been passed down by our ancestors. Livestock is only an activity to domesticate animals, for example buffalo, then use their energy. Fishery is only a simple catch and maintenance of fish and is more dependent on nature. Forestry means the natural cutting of plant trees even with an electric saw.

In modern agriculture, man uses his mind to increase his mastery over all the factors that influence the growth of plants and animals. Agricultural business is an efficient business. Agricultural problems are faced naturally. Irrigation and drainage research can be utilized to obtain maximum results. Plant breeding is carried out to obtain superior varieties, namely high production, response to fertilization, early age and resistance to disease attacks. Forage structures are scientifically prepared and developed with scientific input methods seeds, water, fertilizers, and agricultural equipment and are driven by economic motivation for greater yields and income. Agricultural produce in bulk form is processed to obtain a higher price while the method of preserving agricultural products is developed to obtain a higher value. In general, the history of agriculture began when the ancestors descended from the trees and began to live hunting and nomad (moving). Permanent settlement is a cave which is an early indication of the development of socio-cultural agriculture and so on.

\section{Agriculture and Farming}

Agriculture is a type of production activity based on the growth process of plants and animals. Agriculture in a narrow sense is called people's agriculture, while agriculture in a broad sense includes agriculture in the narrow sense, forestry, livestock and fisheries. These are all important things. Broadly speaking, the notion of Agriculture can be summarized into (1) Production Process; (2) Agriculture or businessmen; (3) Land on which the business is located; (4) Farm business. In this connection, Wilson \& Mosher (1981) states that agriculture is a typical type of production process based on the growth process of plants and animals. Farmers regulate and activate the growth of plants and animals in their farming (farm). This production activity in farming is a business activity, while costs and revenues are important aspects. 
Farming is defined as an organizational unit between work, mode, and management aimed at obtaining production in the agricultural field. In line with this understanding there are four things that need to be considered for farming development. Farm business organizations that are focused on managing the elements of production and business objectives. Farm land ownership patterns. Farm work is focused on the distribution of work and unemployment in farming. Farming capital is focused on the proportion and source of farmer capital.

Basically, as an individual farmer does not have the ability to change the state of his farming business. Therefore, the existence of outside assistance is urgently needed, either directly in the form of business guidance and development or indirectly in the form of incentives that can encourage farmers to accept new things and take change actions. The forms of incentives are as follows: (1) Guarantee the availability of production targets (production inputs) required by farmers in sufficient quantities, at affordable prices, and can always be obtained continuously. (2) Guarantee the coarseness of farming products (3) Guarantee the availability of farm credit that does not burden farmers. (4) Ensuring the existence and continuity of information technology for the development of more productive and efficient farms. (5) Other forms of incentives aimed at stimulating farmers to do more productive and efficient farming.

By looking at this, a parallel understanding can be drawn that in order for the farming carried out by farmers to be more advanced (more productive and efficient), efforts must be made to manage (organize and manage). Internal factors of farming include: (1) managing farmers; (2) Land for farming; (3) labor used in farming; (4) Capital needed in farming (5) The level of technology used in farming; (6) The ability of farmers to allocate family income and the number of family members. External factors of farming, including the availability of means of transportation and communication, aspects related to the marketing of farm produce and materials (yield prices, input production prices, etc.), credit facilities and extension facilities for farmers.

\section{Farmers' Produce Market}

The market for agricultural products referred to here includes the domestic market as well as the foreign market. The marketed agricultural products can be in raw, processed, or industrial raw materials. Basically, there are not many farmers who can sell their own products to the market, either the domestic market, the markets in the cities as well as abroad, because these markets are generally too far away for them (Sheth, 2011). Individual farmers are not difficult to contact buyers in these markets because they do not have adequate means of transportation and do not have the necessary knowledge or facilities for various purposes, such as packaging, storage, processing and nothing else related to the marketing.

Therefore, a good and efficient trading system for agricultural products is needed in supporting the success / success of the market for agricultural products. The functions that must be carried out by the agricultural product trading system are as follows: transportation to markets in big cities and export markets. Storage to protect agricultural products in a good and safe manner, as well as avoiding damage and rot. Further processing of raw or fresh agricultural products into processed products. The financing includes the creation of added value for agricultural products to gain market share and better prices. Management includes the arrangement of the delivery of goods which can be said to be agricultural products both raw and processed to various places at the right time as desired by consumers. 


\section{Conclusion}

Agriculture is a type of production activity based on the growth process of plants and animals. Agriculture in a narrow sense is called people's agriculture, while agriculture in a broad sense includes agriculture in the narrow sense, forestry, livestock and fisheries. These are all important things. Broadly speaking, the notion of Agriculture can be summarized into Production Process, Agriculture or entrepreneur, Land for Business, and Agricultural business. In general, the history of agriculture began when the ancestors descended from the trees and began to live hunting and nomad (moving). Permanent settlement is a cave which is an early indication of the development of socio-cultural agriculture and so on. Agricultural revolution from hunting and farming permanently with characteristics as agricultural extensification, tamed and bred animals, Labor valuable human, library management must be carried out in accordance with the objectives and functions and the market for agricultural products can be carried out in the country as well as in foreign markets. The marketed agricultural products can be in the form of raw, processed, or as industrial raw materials.

\section{References}

Alemanno, A. (2007). The shaping of the precautionary principle by European courts: from scientific uncertainty to legal certainty. Bocconi Legal Studies Research Paper, (1007404).

Altieri, M. A. (2002). Agroecology: the science of natural resource management for poor farmers in marginal environments. Agriculture, ecosystems \& environment, 93(1-3), 124.

Arah, I. K., Kumah, E. K., Anku, E. K., \& Amaglo, H. (2015). An overview of post-harvest losses in tomato production in Africa: causes and possible prevention strategies. Journal of Biology, Agriculture and Healthcare, 5(16), 78-88.

Jacob, J. (2010). New pioneers: The back-to-the-land movement and the search for a sustainable future. Penn State Press.

Marra, M., Pannell, D. J., \& Ghadim, A. A. (2003). The economics of risk, uncertainty and learning in the adoption of new agricultural technologies: where are we on the learning curve?. Agricultural systems, 75(2-3), 215-234.

Phillips, T. W., Berberet, R. C., \& Cuperus, G. W. (2000). Post-harvest integrated pest management. Encyclopedia of food science and technology, 2nd ed. Wiley, New York, 2690-2701.

Pretty, J., Toulmin, C., \& Williams, S. (2011). Sustainable intensification in African agriculture. International journal of agricultural sustainability, 9(1), 5-24.

Sheth, J. N. (2011). Impact of emerging markets on marketing: Rethinking existing perspectives and practices. Journal of marketing, 75(4), 166-182.

Smith, V. L. (1975). The primitive hunter culture, Pleistocene extinction, and the rise of agriculture. Journal of Political Economy, 83(4), 727-755.

Wilson, L. F., \& Mosher, D. G. (1981). How to identify and control pine spittlebug. HT-52. St. Paul, MN: US Department of Agriculture, Forest Service, North Central Forest Experiment Station. 6 p. Notes. 